\title{
Mechanism and Rheological Properties of High-Modulus Asphalt
}

\author{
Xinquan Xu $\left(\mathbb{D},{ }^{1,2}\right.$ Guilin Lu, ${ }^{1}$ Jun Yang $\mathbb{D}^{1},{ }^{1}$ and Xinhai Liu ${ }^{2}$ \\ ${ }^{1}$ School of Transportation, Southeast University, No. 2 Sipailou, Nanjing 210096, China \\ ${ }^{2}$ Guangdong Hualu Transport Technology Co., Ltd, No. 1180 Guangcong Eighth Road, Guangzhou 510435, China
}

Correspondence should be addressed to Jun Yang; yangjun@seu.edu.cn

Received 18 February 2020; Revised 23 March 2020; Accepted 30 March 2020; Published 22 April 2020

Guest Editor: Meng Guo

Copyright (c) 2020 Xinquan Xu et al. This is an open access article distributed under the Creative Commons Attribution License, which permits unrestricted use, distribution, and reproduction in any medium, provided the original work is properly cited.

High-modulus asphalt concrete (HMAC) is considered as an effective paving material for addressing the increasing heavy traffic and rutting problems. Therefore, one high-modulus agent was used in this study to prepare high-modulus asphalt binder with different dosages. The objective of this study is to investigate the performance and modification mechanism of high-modulus asphalt. The effects of high-modulus agent on the viscoelastic properties of asphalt with different dosages were quantified via rheological tests as compared to base binder and styrene-butadiene-styrene- (SBS-) modified asphalt. Moreover, the modification mechanism of the high-modulus agent was examined using fluorescence microscopy and infrared spectrum test. Based on rutting and dynamic modulus tests, the differences of road performances between high-modulus modified asphalt mixture and SBSmodified asphalt mixture were compared. The results demonstrate that the high-modulus agent improves the high-temperature performance and viscoelastic properties of the matrix asphalt. When the dosage increases to $6.67 \%$, the modification effect is better than that of the SBS-modified asphalt. Furthermore, the results of the rutting test show that the high-modulus modified asphalt mixture has better resistance to deformation than the SBS-modified asphalt mixture. The dynamic modulus test further demonstrates that the high-modulus modified asphalt mixture exhibits superior performance in high-temperature range. Fluorescence microscopy shows that the high-modulus agent particles can swell in the asphalt to form polymer links that improve the viscoelastic properties of the asphalt. Based on the results of the infrared spectrum test, it can be concluded that a highmodulus agent changes the asphalt matrix via physical blending modification.

\section{Introduction}

To improve the strength of asphalt pavement and reduce its thickness, France was the first country to adopt highmodulus asphalt concrete (HMAC) [1]. When the complex modulus was larger than $14000 \mathrm{MPa}$ at $15^{\circ} \mathrm{C}$ and $10 \mathrm{~Hz}$, the asphalt concrete can be called HMAC. Practically, researchers determined that HMAC has excellent high-temperature rutting resistance, fatigue resistance, and water stability. Due to these benefits, HMAC is gradually used in the joint and surface layers $[2,3]$. The selection of highmodulus asphalt is extremely important to the production of HMAC. Generally, there are three methods to obtain highmodulus binders that increases the stiffness of asphalt concrete: (1) using hard-grade asphalt binders that have low penetration and high softening points [1]; (2) using a polymer modifier, such as styrene-butadiene-styrene (SBS) and lake asphalt $[4,5]$; and (3) using a high-modulus agent $[6,7]$.

In recent years, in South China, rutting has become one of the most common distresses of asphalt pavement in high temperature and heavy traffic areas. Because HMAC has excellent high-temperature rutting resistance, the investigation on the performance of HMAC has become popular with researchers. Xiao et al. [8] added two types of highmodulus agents to 70\# asphalt and SBS-modified asphalt and studied the performance of modified asphalt and asphalt mixture. They reported that the high-temperature performances of asphalt and asphalt mixture improved after adding a high-modulus agent, but their low-temperature performances slightly decreased. Cao et al. [9] used SBSmodified asphalt and an antirutting agent for compound modification of asphalt concrete and similar conclusions were obtained. Considering that high-modulus admixture 
may reduce the performance of asphalt concrete, Cheng [10] examined the effects of different types of admixtures on the cracking resistance of HMAC and concluded that a mineral fiber admixture could effectively improve the cracking resistance of asphalt concrete. Wang [11] studied the fatigue performance of a high-modulus asphalt mixture and determined that the inorganic modifier calcium sulfate crystal improved the fatigue resistance of HMAC. By investigating and analyzing 80 normal asphalt pavements with HMAC base or conventional asphalt concrete base in Poland, Rys et al. [12] concluded that pavements with high-modulus asphalt bases had a 2.45 times higher probability of being cracked compared to pavements with conventional asphalt concrete bases. Some researchers have investigated the mechanical characteristics of HMAC in the pavement structure and suggested that when HMAC is applied to the middle surface layer, it can bear the maximum shear stress generated by vehicle load better and thus reduce rutting and achieve the best combination of pavement performance and cost. Wang et al. [13] tested the uniaxial penetration and compressive resilient modulus of HMAC, SBS-modified asphalt concrete, and $70 \#$ asphalt concrete at $15^{\circ} \mathrm{C}, 20^{\circ} \mathrm{C}$, $40^{\circ} \mathrm{C}$, and $60^{\circ} \mathrm{C}$. They reported that HMAC has relatively high shear strength and compressive resilient modulus at the different temperatures. Si et al. [14, 15] established the structural models of high-modulus asphalt pavement and conventional asphalt pavement. Using the finite element method and the discrete element method, they investigated the mechanical properties of high-modulus asphalt pavement and reported that HMAC pavement can improve the deformation resistance of asphalt pavement and reduce the deformation of asphalt material in each layer and the rutting potential. Wang et al. [16] and Yang [17] explored the modification mechanism of the high-modulus modifier using scanning electron microscopy, differential scanning calorimetry (DSC), and Fourier transform infrared spectroscopy (FTIR). They explained the mechanism for improving the dynamic modulus of asphalt mixture from the perspective of the interaction between functional groups, additives, and aggregates. To summarize, most of previous research on highmodulus asphalt and HMAC focused on their macroscopic performances and engineering applications. However, there have been very few studies on the mechanism of the highmodulus agent and the rheological properties of highmodulus asphalt. Therefore, the scarcity of relevant research makes it more difficult to determine the function of the highmodulus agent in the asphalt mixture accurately, leading to unstable quality of the high-modulus asphalt mixture.

The study evaluates the effect of the high-modulus agent on the rheological properties of asphalt, along with its mechanism and performance in the application process. The main objectives of this study are (1) to introduce a highmodulus agent as a modifier to improve the performance of asphalt and asphalt mixture, (2) to investigate the influence of high-modulus agent on the rheological properties of asphalt binder, (3) to determine the rutting resistance and dynamic modulus of HMAC, and (4) to study the mechanism of high-modulus agent and its role in improving the performance of asphalt in the process. To achieve these objectives, 70\# asphalt was selected as base asphalt and was modified with a high-modulus agent to obtain high-modulus asphalt. In comparison, the rheological properties of high-modulus asphalt and SBS-modified asphalt at high and low temperatures were studied via rheological testing. The mechanism of high-modulus agent modification in the asphalt was analyzed via fluorescence microscopy and FTIR. Furthermore, the rutting test and dynamic modulus test of the asphalt mixtures were conducted to investigate the road performance. Figure 1 shows the flowchart of the steps and tasks followed in this research project.

\section{Materials and Methods}

\subsection{Materials}

2.1.1. Asphalt Binders and Modifiers. In the comparative study, the 70\# asphalt and SBS-modified asphalt used in the test were provided by Shell and came from the same production batch, and the content of SBS was $4.5 \%$. Highmodulus modified asphalt was prepared using 70\# asphalt that was selected as base binder. The main technical indexes of 70\# asphalt and SBS-modified asphalt were tested by the standard test method of asphalt and asphalt mixture [18].

Table 1 shows the basic properties of the two types of bitumen. It can be seen from Table 1 that the main technical indexes of base asphalt and SBS-modified asphalt meet the requirements of Chinese specification [19].

Crumb rubber has been successfully applied into asphalt pavement as a performance enhancer for many decades, and many studies have proved that asphalt rubber (AR) can provide better rutting and fatigue resistance [20-22]. It was also found that the rubberized asphalt mixture provided higher modulus than the mixture with hard-grade binder and SBS-modified asphalt mixture [23]. In this study, crumb rubber was selected as a high-modulus agent from Dongguan Yinxi Technology Co., Ltd., China. Figure 2 shows the selected high-modulus agent, which is mainly composed of rubber plastic alloy material, and its basic properties are shown in Table 2.

High-modulus modified asphalt was prepared via the high-speed shear method. Table 3 shows the dosage of the high-modulus modifier and the asphalt serial number. The different dosages used in this study were based on the field experience. In Guangdong Province, China, the dosage of high-modulus agent is generally $0.2 \% \sim 0.4 \%$ of the total mass of asphalt mixture. According to the optimal asphalt content (around $4.5 \%$ for AC-20), the ratio of high-modulus agent to asphalt binder is $4.45 \%, 6.67 \%$, and $8.89 \%$, respectively, when the percentage of high-modulus agent by mass of asphalt mixture was $0.2 \%, 0.3 \%$, and $0.4 \%$, respectively. To prepare JG1, JG2, and JG3, 70\# asphalt was heated to $140^{\circ} \mathrm{C}$, and the corresponding dosage of the high-modulus agent was slowly added to the asphalt. Then, the mixture was sheared at $3500 \mathrm{rpm}$ for $15 \mathrm{~min}$ and then at $6000 \mathrm{rpm}$ for $45 \mathrm{~min}$. Both JG0 and FG0 were not mixed with highmodulus agent but high-speed sheared for $60 \mathrm{~min}$ and heated at $140^{\circ} \mathrm{C}$ for $3 \mathrm{~h}$ to simulate the aging process of the blending asphalt binders. 


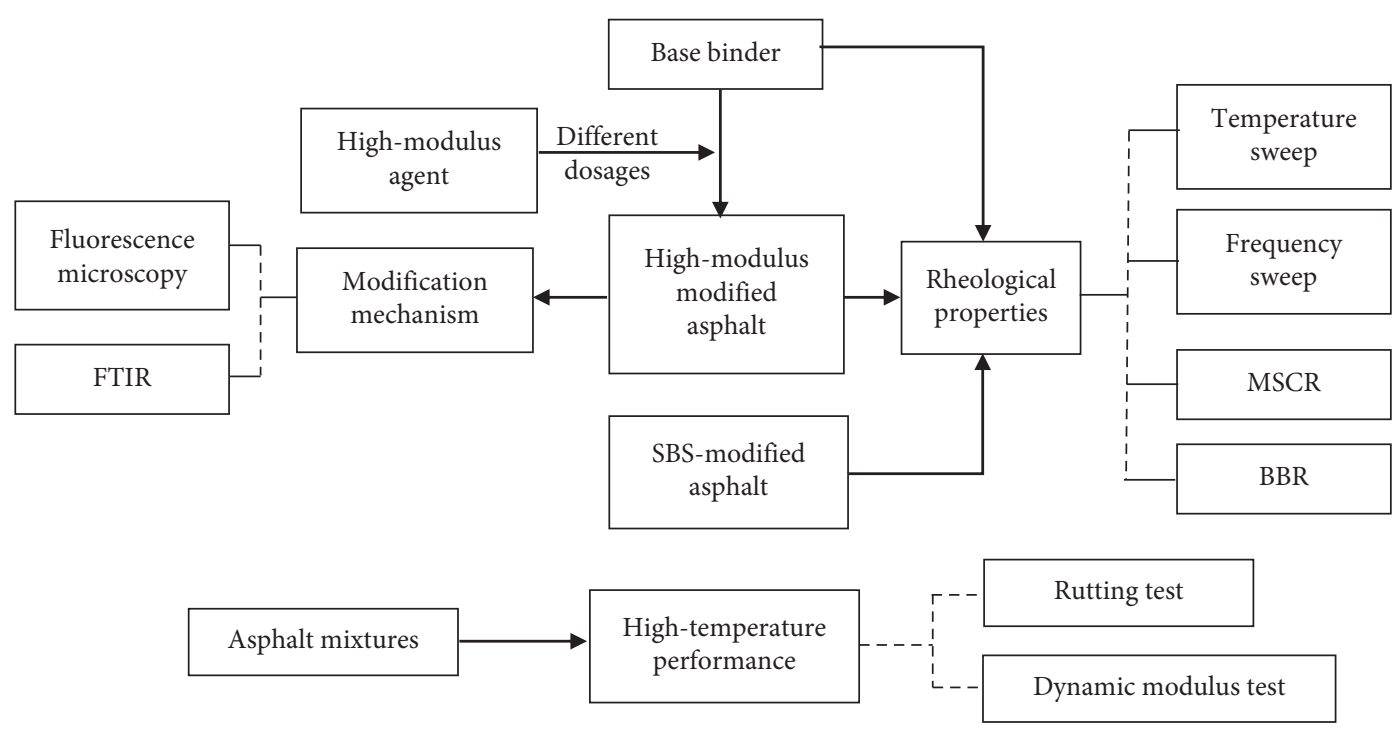

Figure 1: Flowchart of the test program.

TABLE 1: Technical indexes of 70\# asphalt and SBS-modified asphalt.

\begin{tabular}{|c|c|c|c|c|c|c|}
\hline \multirow{2}{*}{ Test properties } & & & \multicolumn{2}{|c|}{ 70\# asphalt } & \multicolumn{2}{|c|}{ SBS-modified asphalt } \\
\hline & & & Test results & Technical index & Test results & Technical index \\
\hline $\mathrm{P} 25^{\circ} \mathrm{C}, 100 \mathrm{~g}, 5 \mathrm{~s}(0.1 \mathrm{~mm})$ & & & 61 & $60-80$ & 55 & $40-60$ \\
\hline$T_{\mathrm{R} \& \mathrm{~B}}\left({ }^{\circ} \mathrm{C}\right)$ & & & 48.5 & $\geq 46$ & 81 & $\geq 60$ \\
\hline \multirow{2}{*}{ Ductility $(\mathrm{cm})$} & $5^{\circ} \mathrm{C}$ & & - & - & 34.4 & $\geq 20$ \\
\hline & $10^{\circ} \mathrm{C}$ & & 18.3 & $\geq 15$ & - & - \\
\hline \multirow{4}{*}{ RTFOT $\left(163^{\circ} \mathrm{C}, 85 \mathrm{~min}\right)$} & Mass loss & & 0.092 & \pm 0.8 & -0.047 & \pm 1.0 \\
\hline & Penetration & & 72 & $\geq 61$ & 80 & $\geq 65$ \\
\hline & Ductility $(\mathrm{cm})$ & $5^{\circ} \mathrm{C}$ & - & - & 22 & $\geq 15$ \\
\hline & & $10^{\circ} \mathrm{C}$ & 6.2 & $\geq 6$ & - & - \\
\hline
\end{tabular}

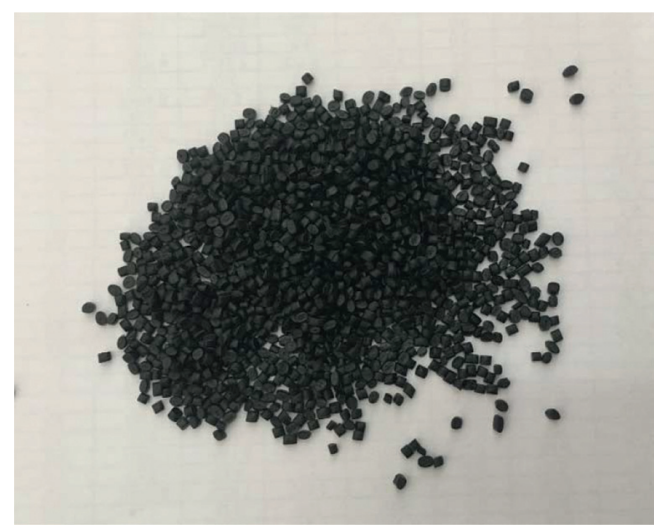

Figure 2: High-modulus agent used in this study.

TABle 2: Technical indexes of the high-modulus agent.

Particle size $(\mathrm{mm})$ Density $\left(\mathrm{g} / \mathrm{cm}^{3}\right)$ Particle morphology Color

\begin{tabular}{llll}
\hline $1-6$ & $0.92-0.98$ & Granular solid & Black
\end{tabular}

2.1.2. Mixtures. To prevent rutting, the high-temperature stability of the middle surface of the asphalt pavement is crucial [14]. To evaluate the practical effect of the highmodulus modifier in road performance, the AC-20 mixture,
TABLE 3: High-modulus agent dosage and asphalt serial number.

\begin{tabular}{lccccc}
\hline Asphalt type & $\begin{array}{c}70 \# \\
\text { asphalt }\end{array}$ & \multicolumn{4}{c}{ SBS-modified asphalt } \\
\hline $\begin{array}{l}\text { High-modulus agent dosage } \\
\text { (\%) }\end{array}$ & 0 & 4.45 & 6.67 & 8.89 & 0 \\
Serial number & JG0 & JG1 & JG2 & JG3 & FG0 \\
\hline
\end{tabular}

Note. The high-modulus agent content is the ratio of the high-modulus agent to the asphalt quality.

which is commonly used in the middle surface of asphalt pavement, was selected to explore the effect of the highmodulus modifier on the high-temperature performance of asphalt mixture. Table 4 shows the gradation used in the test. The asphalt consumption is $4.14 \%$, and the designed void ratio is $4.1 \%$.

\subsection{Test Methods}

2.2.1. Dynamic Shear Rheological Test. The dynamic shear rheological test is considered as an important method to investigate the influence of the loading conditions and temperature on the properties of the asphalt as well as to analyze the viscoelastic properties of asphalt [24, 25]. The Malvern Kinexus dynamic shear rheometer (DSR) was used 
TABLE 4: Gradation of the AC-20 asphalt mixture.

\begin{tabular}{lcccccccccccc}
\hline Sieve size $(\mathrm{mm})$ & 26.5 & 19 & 16 & 13.2 & 9.5 & 4.75 & 2.36 & 1.18 & 0.6 & 0.3 & 0.15 & 0.075 \\
\hline Passing rate $(\%)$ & 100 & 96.4 & 85.2 & 73.2 & 57.1 & 33.2 & 25.2 & 18.8 & 14 & 10.4 & 8.2 & 6 \\
\hline
\end{tabular}

in the temperature-sweep test and the frequency-sweep test. In the temperature-sweep test, the diameter of the plates was $25 \mathrm{~mm}$ and the gap between two plates was $1 \mathrm{~mm}$, the control strain was set at $0.1 \%$, the control frequency was $1.592 \mathrm{~Hz}(10 \mathrm{rad} / \mathrm{s})$, and the temperature range was from $58^{\circ} \mathrm{C}$ to $112^{\circ} \mathrm{C}$ with an interval of $6^{\circ} \mathrm{C}$. For the frequencysweep test, the diameter of the plates was $25 \mathrm{~mm}$ with a gap of $2 \mathrm{~mm}$. The control strain was set at $0.1 \%$. The selected temperatures were 5,20 , and $35^{\circ} \mathrm{C}$, and the frequency range was $0.1-100 \mathrm{rad} / \mathrm{s}$. Each order of magnitude had 10 frequency points, thus yielding 30 frequency points. Based on DSR frequency-sweep test results, the sigmoidal function $[26,27]$ was used to fit the master curves of the complex shear modulus of the asphalt, as shown in equation (1). Considering $20^{\circ} \mathrm{C}$ as the reference temperature, based on the time-temperature superposition principle, the Williams-Landel-Ferry (WLF) equation was used to calculate the shift factor of the complex shear modulus at different temperatures. The WLF equation is shown in equation (2).

$$
L g\left|G^{*}\right|=\delta+\frac{\alpha}{1+e^{\beta+\gamma L g f_{r}}},
$$

where $\left|G^{*}\right|$ is the complex shear modulus (GPa); $f_{r}$ is the reduced frequency at the reference temperature $(\mathrm{Hz})$; and $\delta$, $\alpha, \beta$, and $\gamma$ are constants.

$$
\operatorname{Lg} \alpha_{T}=-\frac{C_{1}\left(T-\mathrm{T}_{0}\right)}{C_{2}+\left(T-\mathrm{T}_{0}\right)}
$$

where $T$ is the test temperature $\left({ }^{\circ} \mathrm{C}\right) ; \alpha_{T}$ is the shift factor at temperature $T ; T_{0}$ is the reference temperature $\left({ }^{\circ} \mathrm{C}\right)$; and $\mathrm{C}_{1}$ and $\mathrm{C}_{2}$ are constants. Two replicates were prepared and tested for each type of binder.

2.2.2. Multistress Creep Recovery Test. Many studies have shown that $\mathrm{G}^{*} / \sin \delta$ cannot be used to evaluate accurately the high-temperature properties of the polymer-modified asphalt $[28,29]$. NCHRP 9-10 proposed a method of evaluating the performance of modified asphalt based on multistress creep recovery (MSCR) tests [30]. The creep recovery rate $(R)$ was used to characterize the elastic deformation capacity of the asphalt binder, the unrecoverable creep compliance $\left(J_{\mathrm{nr}}\right)$ was used to characterize the resistance potential of asphalt binder to permanent deformation accumulation, and the unrecoverable creep compliance difference $\left(J_{\text {nr-diff }}\right)$ was used to characterize the sensitivity of asphalt binder to loading stress. Note that the higher $R$ value implies the improvement of elastic deformation capacity of the asphalt binder, lower $J_{\mathrm{nr}}$ indicates the increase of permanent deformation resistance, and $J_{\text {nr-diff }}$ decreases with the decrease of stress sensitivity. The loading mode of the MSCR test is close to the actual situation of the pavement load, which can demonstrate the viscoelastic characteristics of asphalt well. In this study, the temperature of $60^{\circ} \mathrm{C}$ was selected, and MSCR test was conducted to evaluate the viscoelastic characteristics of high-modulus modified asphalt according to AASHTO TP-70. Two replicates were prepared and tested for each binder.

2.2.3. Bending Beam Rheological Test. The bending beam rheometer (BBR) test is a grading test method of evaluating the low-temperature performance of asphalt recommended by the Strategic Highway Research Program (SHRP) [18, 25]. In the test, the deflection values were used to calculate the stiffness of asphalt binder; the equation is shown as follows:

$$
S(t)=\frac{\mathrm{PL}^{3}}{4 b h^{3} \delta(t)},
$$

where $P$ is the applied constant load $(100 \mathrm{~g}$ or $0.98 \mathrm{~N}) ; L$ represents the distance between beam supports $(102 \mathrm{~mm}) ; b$ represents beam width $(12.7 \mathrm{~mm}) ; h$ is beam thickness $(6.25 \mathrm{~mm}) ; S(t)$ represents asphalt binder stiffness at a specific time (MPa); and $\delta(t)$ is the deflection at a specific time $(\mathrm{mm})$.

Stiffness value was calculated at $60 \mathrm{~s}$, and the slope of stiffness versus time is called $m$-value. The creep stiffness from the BBR test is a measure of the development of thermal stresses in the asphalt binder. The two parameters are used as indicators of asphalt binder to characterize the thermal cracking potential at the low temperature. With a higher $S$, the asphalt becomes more brittle at low temperature, and it is more likely to crack at low temperature. With a higher $m$ value, the stress relaxation performance the asphalt is better, and the possibility of low-temperature cracking decreases. The grading standard is that the stiffness modulus $(S)$ should not exceed $300 \mathrm{MPa}$, and the creep rate $(m)$ should not be less than 0.3 . In this study, CANNON BBR was used and the test temperature was $-10^{\circ} \mathrm{C}$. Two replicates were prepared and tested for each binder.

2.2.4. Fluorescence Microscopy. Fluorescence microscopy was used to observe the distribution of the modifier in the asphalt. By using excitation light of different colors, the fluorescent dye samples, which are difficult to be observed using an ordinary microscope, were clearly observed and identified. In Figure 3, the magnification of the objective lens was 10-100 times and that of the eyepiece was 10 times. Three replicates were tested for each prepared binder.

2.2.5. Infrared Spectrum Test. In this experiment, the attenuated total reflection method was used in the Agilent Cary 630 FTIR (Figure 4) to conduct infrared spectrum detection on the high-modulus modifier, 70\# asphalt, and high-modulus modified asphalt samples, so as to determine the basic chemical composition and modification 


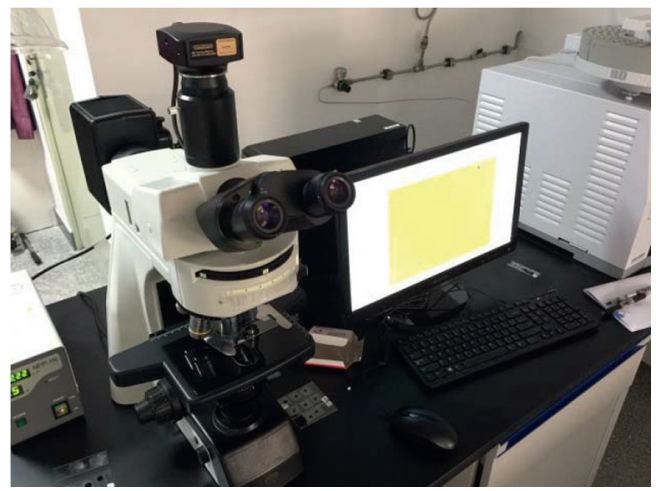

FIGURE 3: Fluorescence microscope.

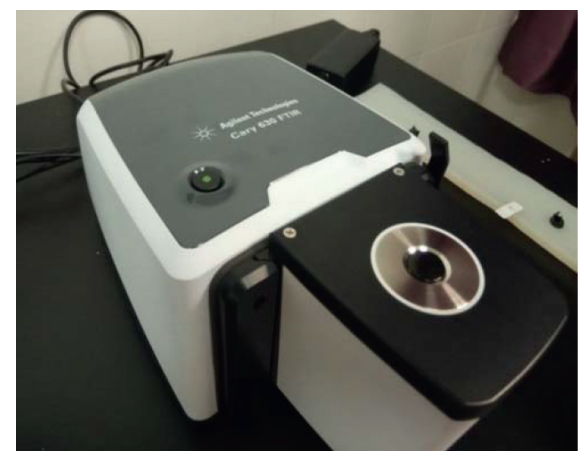

(a)

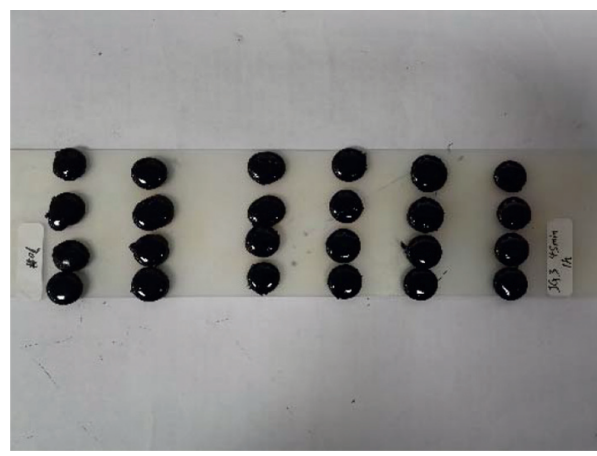

(b)

FIgURE 4: Infrared spectrum test of asphalt: (a) infrared spectrometer; (b) asphalt samples.

mechanism of the high-modulus modifier. Three replicates were tested for each prepared binder.

2.2.6. Rutting Test. The rutting test was used to test the hightemperature antirutting capacity of the asphalt mixture by simulating the actual wheel movement on the asphalt pavement by the reciprocating movement of the wheel on the plate-shaped test piece. HMAC is widely used in South China to address the serious rutting problem. Considering these two factors including high temperature and precipitation in this area, two sets of rutting tests were conducted at $60^{\circ} \mathrm{C}$ and $70^{\circ} \mathrm{C}$ to evaluate the high-temperature rutting resistance of the asphalt mixture. Furthermore, a drying group and a soaking group were set to analyze the water stability. Additionally, considering the overload phenomenon, the test loading was increased from 0.7 to $0.9 \mathrm{MPa}$ for three comparative analyses. Following the rutting test method of asphalt mixture (T0719-2011) [18], the size of the rutting test samples was $300 \times 300 \times 50 \mathrm{~mm}$, and dynamic stability (DS) was calculated as follows:

$$
\mathrm{DS}=\frac{42 \times(60-45)}{d_{60}-d_{45}},
$$

where DS is the dynamic stability in cycle/mm; $d_{60}$ is the rutting depth at $60 \mathrm{~min}$ in $\mathrm{mm}$; and $d_{45}$ is the rutting depth at $45 \mathrm{~min}$ in $\mathrm{mm}$. Two replicates were tested for each prepared sample.
2.2.7. Dynamic Modulus Test. Due to the fact that the modulus of HMAC is different from that of conventional asphalt concrete mixture $[14,26]$, the dynamic modulus test was used. The multifunctional material testing machine (UTM-100) was used for this test, and the test samples were $100 \mathrm{~mm}$ in diameter and $150 \mathrm{~mm}$ in height. The dynamic modulus test was performed with the loading frequencies of $0.1,0.5,1,5,10$, and $25 \mathrm{~Hz}$ at $4^{\circ} \mathrm{C}, 15^{\circ} \mathrm{C}, 25^{\circ} \mathrm{C}, 35^{\circ} \mathrm{C}, 45^{\circ} \mathrm{C}$, and $60^{\circ} \mathrm{C}$. The test was conducted from low temperature to high temperature with the decrease of loading frequencies so as to enhance the testing accuracy. The dynamic modulus test was conducted with constant strain, making sure that the stressstrain relationship within the loading range remained linear. In the control mode, sinusoidal load was applied to the samples, and the strain was controlled between 85 and $115 \mu \varepsilon$. The room temperature was selected as the reference temperature. According to the time-temperature superposition principle, the master curve of the dynamic modulus of the asphalt mixture was fitted using the sigmoidal function. Two replicates were prepared and tested for each type of sample.

\section{Results and Discussion}

\subsection{Rheological Properties of Asphalt}

3.1.1. Analysis of Temperature-Sweep Test Results. Figure 5 shows the temperature-sweep test results. In Figure 5(a), it can be seen that the complex modulus $\left(\mathrm{G}^{*}\right)$ of 


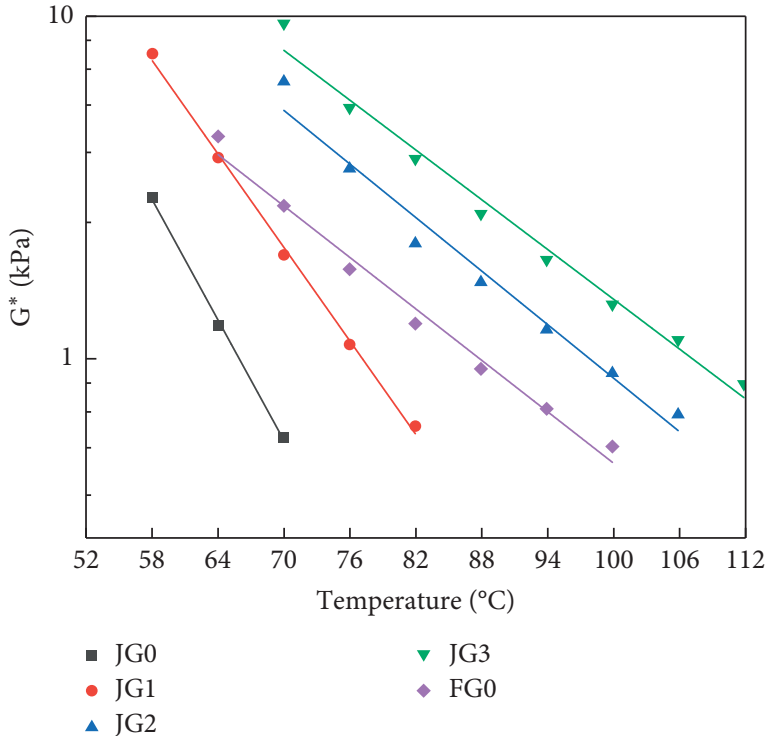

(a)

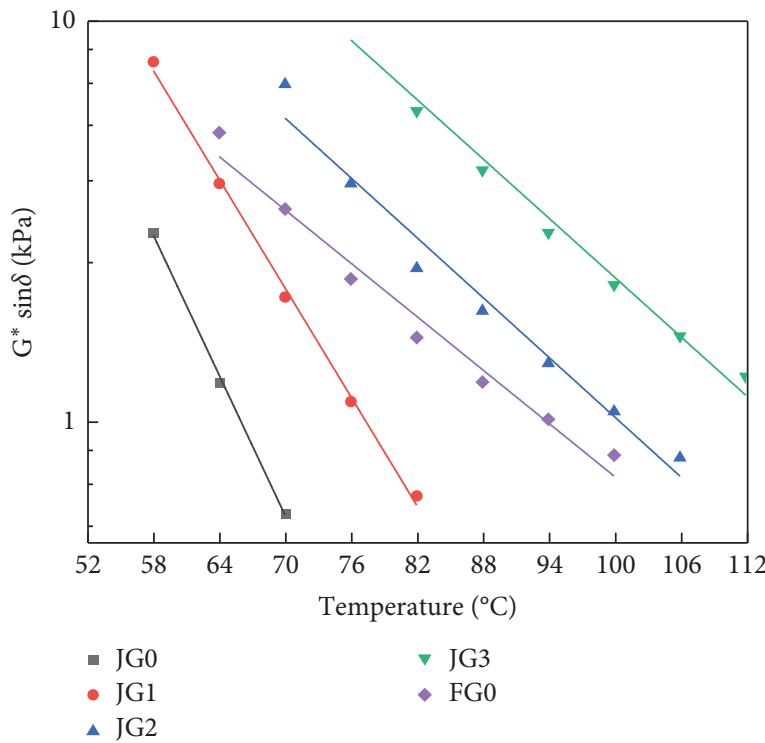

(c)

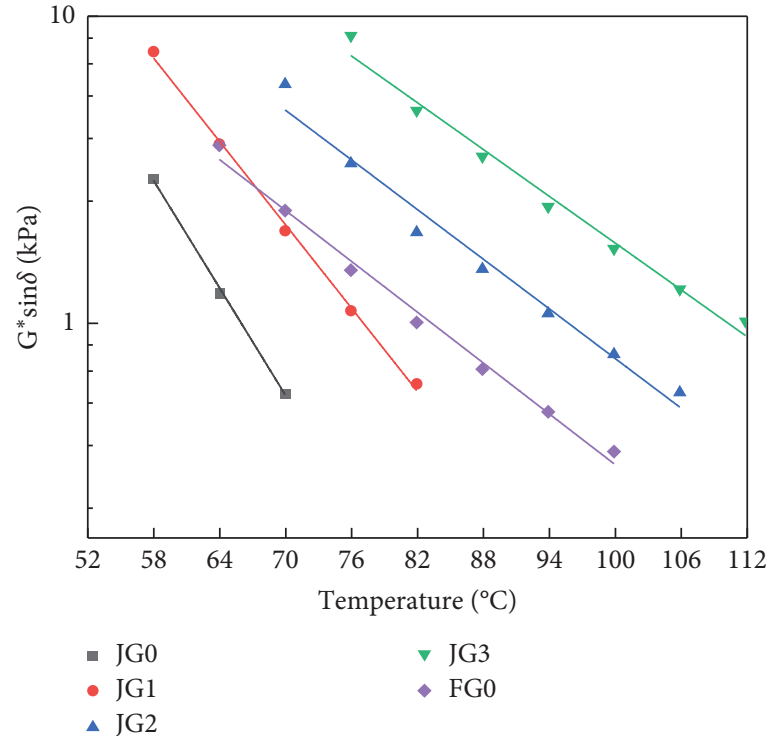

(b)

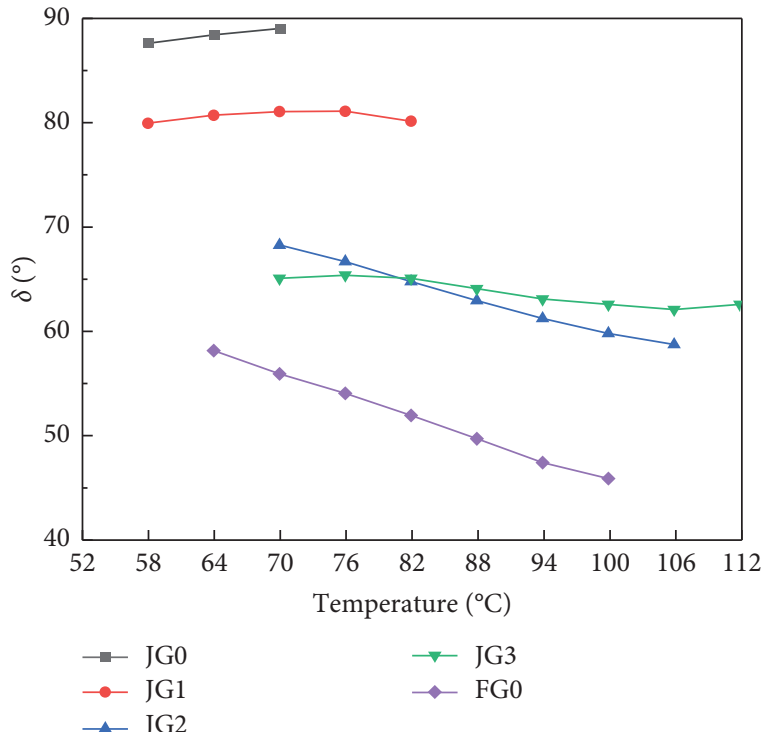

(d)

FIGURE 5: Relationship between the viscoelastic properties of asphalt and temperature: (a) complex modulus versus temperature; (b) fatigue factor versus temperature; (c) rutting factor versus temperature; (d) phase angle versus temperature.

the asphalt decreases with the increase of temperature, indicating the poor deformation resistance of asphalt at high temperature. Compared with JG0, the complex modulus of JG1, JG2, and JG3 with the high-modulus modifier considerably improved. And with the content of the high-modulus agent increasing, the complex modulus increases. Taking the temperature of $70^{\circ} \mathrm{C}$ as an example, the complex modulus of JG1, JG2, and JG3 increases by 2.4, 9.9, and 15.1 times, respectively, compared with the figure for JG0. If the content of the high-modulus agent is equal to that of SBS (4.5\%), SBSmodified asphalt has a higher complex modulus as the temperature surpasses $64^{\circ} \mathrm{C}$. With the content of the highmodulus agent increasing to $6.67 \%$, the complex modulus of the high-modulus modified asphalt is higher than that of the
SBS-modified asphalt. This indicates that the high-modulus modified asphalt has better high-temperature stability when a certain content of the high-modulus agent is used. With highmodulus agent content increasing, the slopes of the complex modulus curves rapidly decrease and then remain stable, which indicates that the addition of the high-modulus agent may lead to the decline of the temperature sensitivity of the asphalt. When the content increases to $6.67 \%$ or more, no significant difference in the slopes of curves can be found among the high-modulus modified asphalt and the SBSmodified asphalt. This means that the two types of asphalt show similar temperature sensitivity.

Figures 5(b) and 5(c) show the fatigue factors and the rutting factors of the samples versus temperature. The 
change trends of both are consistent with the complex modulus, which demonstrates that the high-modulus modified asphalt containing $6.67 \%$ high-modulus agent or more has better high-temperature performance and fatigue performance than the SBS-modified asphalt. The result of better rutting resistance of high-modulus modified asphalt is consistent with previous finding in the literature [23]. In Figure 5(d), it can be observed that the phase angle of asphalt significantly decreases with the increase of high-modulus agent content, from $89.0^{\circ}$ of JG0 to $68.2^{\circ}$ of JG2 at $70^{\circ} \mathrm{C}$; it means that the addition of the high-modulus modifier can contribute to the improvement of the elastic performance of asphalt at high temperature. However, when the content was higher than $6.67 \%$, the decrease of the phase angle is not obvious. It may be attributed to the formation and enhancement of a polymer link network with relatively small content, which improves the elastic properties of the asphalt. But the additional increase has no significant effect on the link network, indicating that the improvement of the elastic properties of the asphalt with the addition of the highmodulus agent is limited. It also can be found that the SBSmodified asphalt shows the lowest phase angle, which indicates that SBS-modified asphalt has better elastic recovery performance than 70\# asphalt. And the addition of the highmodulus modifier can narrow the gap between the two types of asphalt to some extent.

3.1.2. Analysis of Frequency-Sweep Test Results. Selecting $20^{\circ} \mathrm{C}$ as the reference temperature, the master curves of the complex shear modulus and the main curve of the phase angle are shown in Figure 6.

As shown in Figure 6(a), compared with the SBSmodified asphalt, 70\# asphalt has a higher modulus at higher frequencies $\left(10^{0}-10^{4} \mathrm{rad} / \mathrm{s}\right)$ and a lower modulus at low frequencies $\left(10^{-3}-10^{\circ} \mathrm{rad} / \mathrm{s}\right)$. According to the time-temperature superposition principle, low frequency is equivalent to a temperature increase. Similar to the results obtained before, the SBS-modified asphalt shows lower temperature sensitivity and better high-temperature performance. After the addition of the high-modulus modifier, the master curve of the complex shear modulus of the asphalt reflects a positive correlation. In the high-frequency band $\left(10^{2}-10^{4} \mathrm{rad} / \mathrm{s}\right)$, the complex shear modulus of the asphalt somewhat changes with the content. In the low-frequency band $\left(10^{-3}-10^{2} \mathrm{rad} / \mathrm{s}\right)$, if the content of the high-modulus agent is not more than $6.67 \%$, the complex shear modulus of the asphalt significantly increases with the increase of the content under the same loading frequency, indicating that the high-temperature performance of the high-modulus modified asphalt considerably improves. When the dosage is further increased, the complex modulus does not continue to increase, which confirms that the improvement of the high-temperature performance of the asphalt is limited despite the addition of the high-modulus agent. Similar to Figure 6(a), the master curves of the phase angle in Figure 6(b) show that the addition of the high-modulus agent can effectively improve the viscoelasticity of the asphalt, reduce the phase angle of the asphalt, and enhance the elastic recovery ability of the asphalt. In the low-frequency band $\left(10^{-3}-10^{-1} \mathrm{rad} / \mathrm{s}\right)$, the phase angles of JG0 and JG1 are significantly higher than those of the SBS-modified asphalt, which indicates that JG0 and JG1 are more similar to viscoelastic fluids at high temperature and more likely to flow compared to the SBS-modified asphalt. With further increase in the high-modulus agent content, the viscoelasticity of the asphalt significantly improves. When the content is $6.67 \%$, the modified asphalt has the best elastic performance and viscoelasticity. The increase in the content of the asphalt makes the phase angle of the asphalt increase, which may be attributed to the heterogeneous dispersion of the highmodulus modifier and the weakening of the link with the asphalt, leading to the increase of the phase angle of the asphalt.

3.1.3. Analysis of the MSCR Results. The MSCR results are shown in Figure 7 . In both stress conditions $(0.1 \mathrm{kPa}$ or $3.2 \mathrm{kPa}$ ), with the increase of high-modulus agent, the shear strain of the asphalt gradually decreases, and when the highmodulus agent content increases to $6.67 \%$, the strain response of the asphalt remains stable, which demonstrates that the addition of the high-modulus agent improves the deformation resistance of the asphalt. It is also found that JG2 showed lower strain response compared with the SBSmodified asphalt, indicating the high-temperature deformation resistance of JG2 is better than that of the SBSmodified asphalt. Moreover, comparing the shear-strain curves of the 70\# asphalt, the high-modulus modified asphalt, and the SBS-modified asphalt, it can be seen that the shear strain of the 70\# asphalt increases gradually during the loading time but does not significantly recover during the unloading time. However, the shear strain of SBS-modified asphalt during the loading time is significantly less than that of 70\# asphalt, and the residual shear strain of creep stress after unloading is smaller, which shows that SBS-modified asphalt has better elastic recovery performance than 70\# asphalt at high temperature.

Table 5 shows the calculation results of the rheological parameters of the 70\# asphalt, the high-modulus modified asphalt, and the SBS-modified asphalt based on the MSCR test. With the increase of high-modulus agent content, $R$ value increases considerably and then tends to remain stable, and $J_{\mathrm{nr}}$ decreases first and then tends to remain stable. This demonstrates that the addition of the high-modulus additive can lead to the enhancement of the high-temperature elastic deformation recovery capacity and the improvement of the antirutting ability. At $0.1 \mathrm{kPa}$, the $R$ values of JG2 and JG3 are higher than those of SBS-modified asphalt, whereas $J_{\mathrm{nr}}$ values of JG2 and JG3 are lower than those of the SBSmodified asphalt. At $3.2 \mathrm{kPa}$, the $J_{\mathrm{nr}}$ values of JG2 and JG3 are $0.184 \mathrm{kPa}^{-1}$ and $0.154 \mathrm{kPa}^{-1}$, respectively, which are lower than those of the SBS-modified asphalt. Moreover, the $R$ value of JG3 is $48.2 \%$, which is slightly lower than that of the SBS-modified asphalt. With the increase of high-modulus agent content, the $J_{\mathrm{nr} \text {-diff }}$ value of the high-modulus modified asphalt increases gradually, which is greater than those of the 70\# matrix asphalt and the SBS-modified 


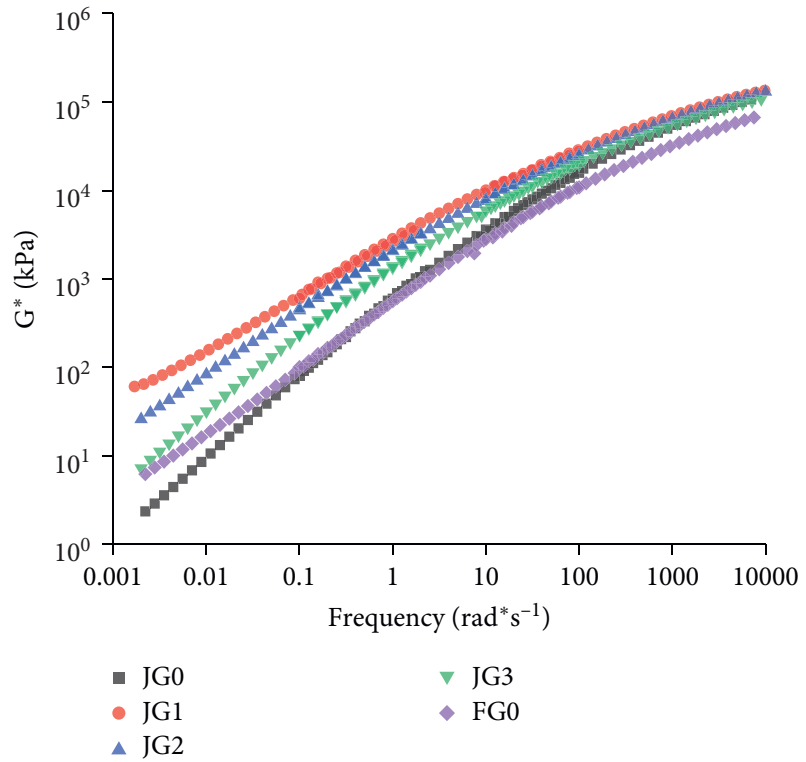

(a)

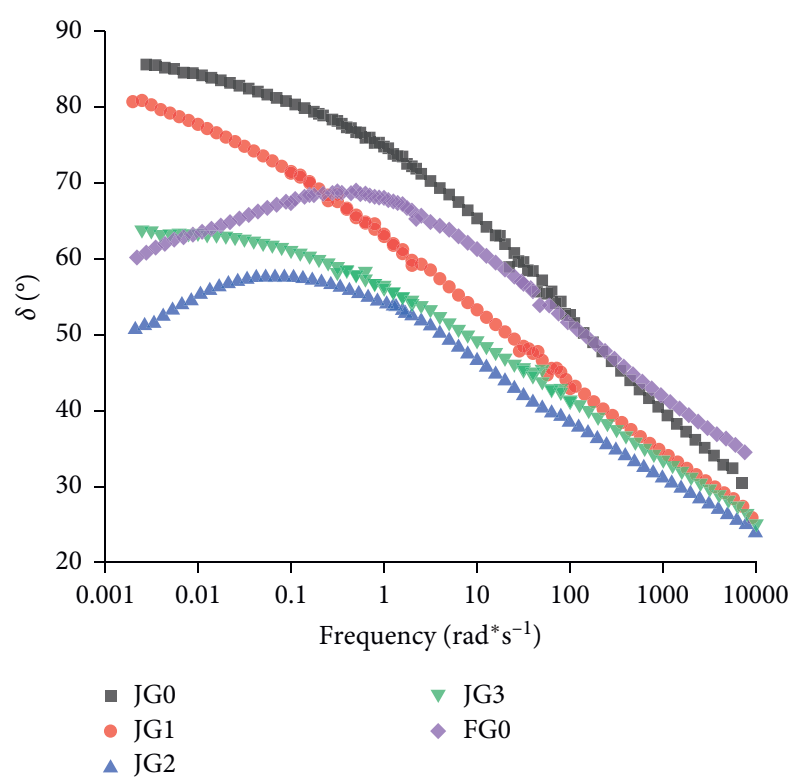

(b)

FIGURE 6: Frequency-sweep test results: (a) master curve of complex shear modulus; (b) master curve of phase angle.

asphalt, indicating that the high-modulus additive increases the sensitivity of asphalt to load.

\subsubsection{Low-Temperature Performance of Asphalt. Figure 8} shows the BBR test results for the high-modulus modified asphalt. With the increase of high-modulus additive content, the creep stiffness of the asphalt increases, whereas the $m$ value gradually decreases. This indicates that the addition of the high-modulus agent increases the stiffness of the asphalt but reduces its flexibility, which makes it stiffer and more brittle and thus causes damage to its low-temperature performance. Therefore, the determination of the content of the high-modulus agent needs more caution. According to the test results for the high- and low-temperature performance of the high-modulus modified asphalt with different high-modulus agent contents, adding $6.67 \%$ high-modulus agent to 70\# asphalt is recommended for preparing HMAC in engineering applications.

\subsection{High-Temperature Performance of Asphalt Mixtures}

3.2.1. Analysis of Rutting Test Results. The rutting test was conducted on three types of asphalt mixtures using 70\# asphalt, SBS-modified asphalt, and JG2 as binder, and the test results are shown in Table 6. Obviously, the addition of the high-modulus agent can significantly improve the DS of the 70\# asphalt mixture. Moreover, the improvement effect of high modulus-modified asphalt is better compared with SBS-modified asphalt under all test conditions. Under the standard test conditions $\left(0.7 \mathrm{MPa}, 60^{\circ} \mathrm{C}\right)$, the DS of the highmodulus modified asphalt mixture is 6.8 times more than that of the base asphalt mixture, whereas there is 5.2 times increase in the SBS-modified asphalt mixture. Under hightemperature and heavy-load conditions $\left(0.9 \mathrm{MPa}, 70^{\circ} \mathrm{C}\right)$, the high-modulus agent has a particularly prominent effect on the high-temperature performance of the mixture. After adding the high-modulus agent, the DS of the asphalt mixture increases significantly. Compared with the base asphalt mixture, there is 12.4 times increase in the highmodulus asphalt mixture. And the DS of JG2 mixture is about 40 percent higher than that of the SBS-modified asphalt mixture, which demonstrates that the HMAC has better rutting resistance under special conditions such as high temperature and heavy load. When the humidity increased during the test, the DS of the three asphalt mixtures decreased. However, the decrease in the DS of the highmodulus modified asphalt mixture was only $11.1 \%$, which was considerably lower than those of the 70\# asphalt mixture (22.2\%) and the SBS-modified asphalt mixture (19.9\%), confirming that the asphalt mixture modified by the highmodulus agent has good water stability.

\subsubsection{Analysis of Dynamic Modulus Test Results.} Figure 9 shows the dynamic modulus master curves of HMAC and the SBS-modified asphalt mixture; it can be seen that HMAC has higher modulus under both high- and lowtemperature conditions. This conclusion is consistent with the results of the asphalt frequency-sweep test, which further confirms that high-modulus modified asphalt has good applicability in high-temperature range.

\subsection{Modification Mechanism}

3.3.1. Fluorescence Microscopic Observations. The mechanical properties of polymers come from the entanglement between chains. Only when the entanglement between different molecules is formed in the interface area, can the interface have a certain mechanical strength. Based on the 


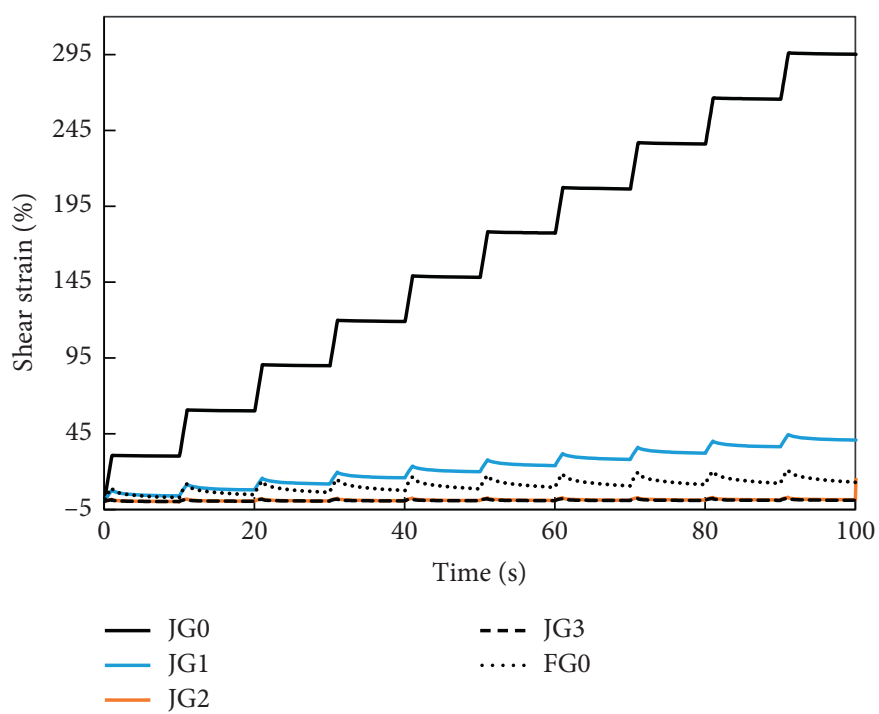

(a)

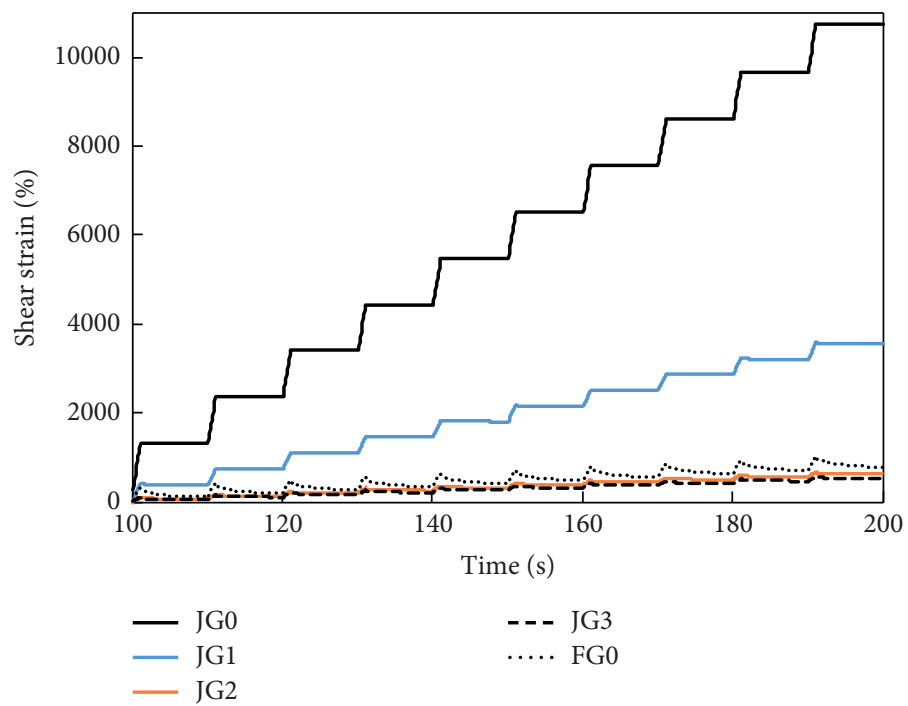

(b)

Figure 7: MSCR test curves at $60^{\circ} \mathrm{C}$ : (a) $0.1 \mathrm{kPa}$; (b) $3.2 \mathrm{kPa}$.

TABLE 5: MSCR test results.

\begin{tabular}{lcccccc}
\hline Rheological parameters & Stress & JG0 & JG1 & JG2 & JG3 & FG0 \\
\hline \multirow{2}{*}{$R(\%)$} & $0.1 \mathrm{kPa}$ & 2.3 & 48.4 & 95.4 & 98.1 & 89.2 \\
& $3.2 \mathrm{kPa}$ & -0.3 & 3.4 & 41.3 & 48.2 & 77.8 \\
$J_{\mathrm{nr}}\left(\mathrm{kPa}^{-1}\right)$ & $0.1 \mathrm{kPa}$ & 2.907 & 0.400 & 0.007 & 0.002 & 0.095 \\
$J_{\text {nr-diff }}(\%)$ & $3.2 \mathrm{kPa}$ & 3.222 & 1.096 & 0.184 & 0.154 & 0.211 \\
\hline
\end{tabular}

minimum energy principle, the addition of modifiers causes redistribution in the system, and the system tends to a new equilibrium by reducing the surface energy [28]. Moreover, some polymer segments of the modifier particles diffuse into the asphalt phase to form an interface layer, which slows down the movement of the molecules. Furthermore, some polymers have high stability and strong network structure with the asphalt molecular chain, which helps improve the mechanical properties of the asphalt mixture. In addition, the polar graft copolymer component present in the high-modulus agent can lead to the formation of a stronger polymer link between aggregate surface and asphalt compared to the structural asphalt and can improve the modulus and the high-temperature performance of the asphalt mixture. According to previous studies [31, 32], one highmodulus modifier (a polyolefin modifier) tends to form a network in the binder system possibly because of the swelling through fluorescence microscope observation. 


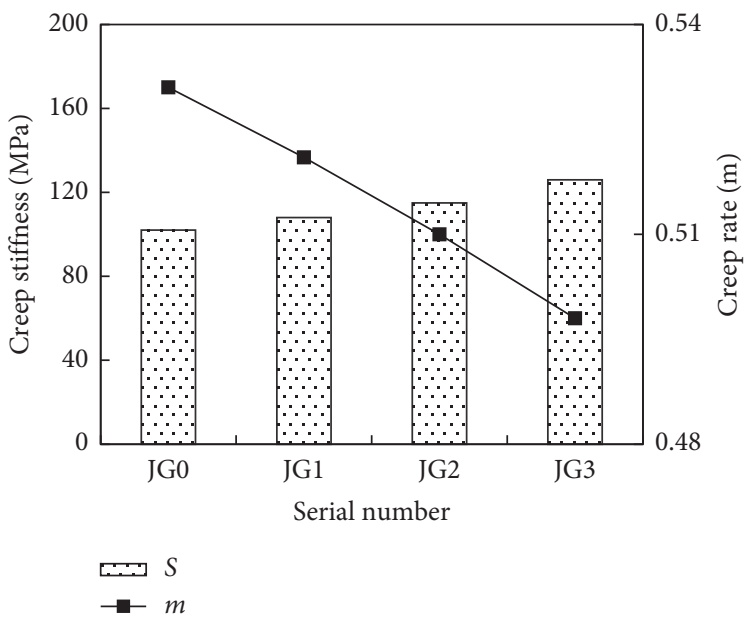

Figure 8: The relationship between $S, m$, and the high-modulus modified asphalt content.

TABLe 6: Dynamic stability results (cycle/mm).

\begin{tabular}{lccc}
\hline Test conditions & \multicolumn{2}{c}{ Asphalt binder type } \\
& 70\# asphalt & SBS-modified asphalt (FG0) & High-modulus asphalt (JG2) \\
\hline $0.7 \mathrm{MPa}, 60^{\circ} \mathrm{C}$, dry & 1866 & 9856 & 12670 \\
$0.7 \mathrm{MPa}, 60^{\circ} \mathrm{C}$, wet & 1452 & 7892 & 11253 \\
$0.7 \mathrm{MPa}, 70^{\circ} \mathrm{C}$, dry & 868 & 6524 & 7624 \\
$0.9 \mathrm{MPa}, 70^{\circ} \mathrm{C}$, dry & 233 & 2112 & 2886 \\
\hline
\end{tabular}

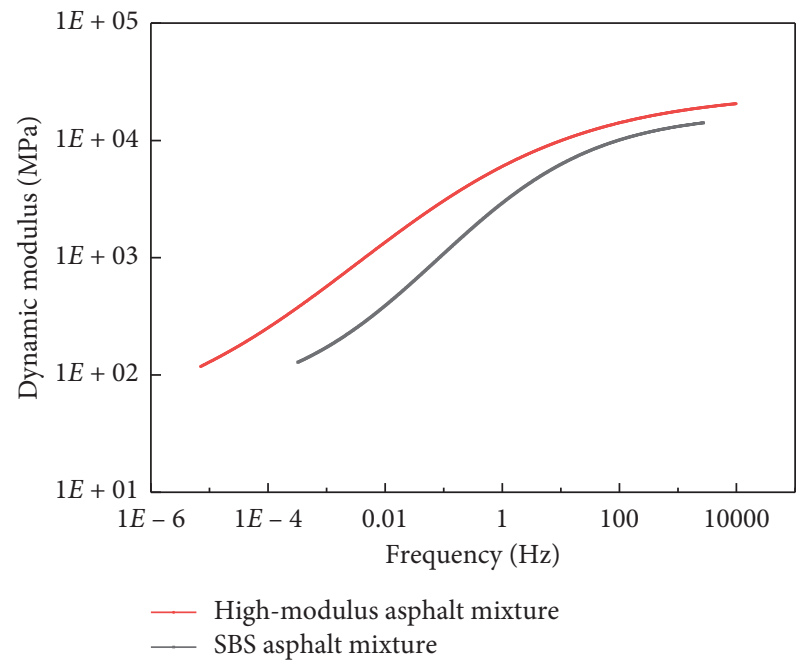

Figure 9: Dynamic modulus master curve of the asphalt mixtures.

Based on this, the modification mechanism of the high-modulus modifier used in this study was investigated using fluorescence microscopic test. Figure 10 shows a fluorescent micrograph of JG3 at different development times. There is a clear interface between the high-modulus agent and the asphalt before high-temperature development. With the increase of the development time, the difference between the yellow pattern (representing the high-modulus agent) and the orange background (representing the asphalt) becomes smaller, and the boundary between them becomes fuzzy gradually. This shows that the sheared high-modulus agent particles can swell and develop in the high-temperature environment, absorb the light components of the asphalt, form polymer links, distribute more homogeneously in the origin asphalt, and improve the viscoelastic properties and high-temperature performance of asphalt.

3.3.2. Infrared Spectrum Analysis. Apart from the observed results from fluorescence microscope, using infrared spectrum test can also help to investigate the modification mechanism of high-modulus agent in the binder. In the previous study [17], Yang reported that there was neither new chemical reaction nor the formation of new functional groups in the asphalt containing one high-modulus modifier through infrared spectrum test. Figure 11 shows the infrared spectrum of the high-modulus modifier. There are four obvious sharp infrared absorption peaks of the high-modulus modifier at $715,1468,2847$, and $2914 \mathrm{~cm}^{-1}$. The $715 \mathrm{~cm}^{-1}$ peak represents the in-plane rolling vibration absorption peak of $-\left(\mathrm{CH}_{2}\right) \mathrm{n}-(n \geq 4)$, the $1468 \mathrm{~cm}^{-1}$ peak represents the bending vibration absorption peak of $-\mathrm{CH}_{2-}$, the $1468 \mathrm{~cm}^{-1}$ peak represents the symmetric stretching vibration absorption peak of $-\mathrm{CH}_{2}-$, and the $2914 \mathrm{~cm}^{-1}$ peak represents the asymmetric stretching vibration absorption peak of- $\mathrm{CH}_{2}-$. Figures $12(\mathrm{a})-12$ (c) show the infrared spectrum of the high-modulus modifier, the 70\# matrix asphalt, and the high-modulus modified asphalt JG2, respectively. The infrared spectrum of the high-modulus modified asphalt is the superposition of the infrared spectrum of the high-modulus modifier and the infrared spectrum of the 70\# asphalt. There is no new infrared absorption peak in the infrared spectrum of the high-modulus modified 


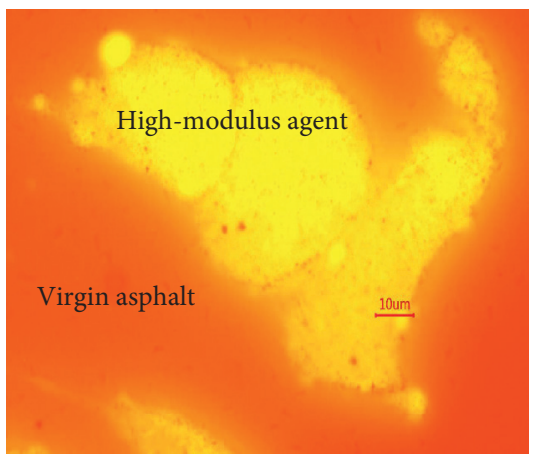

(a)

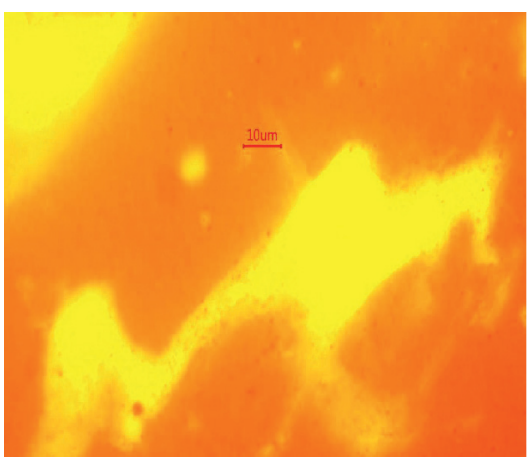

(b)

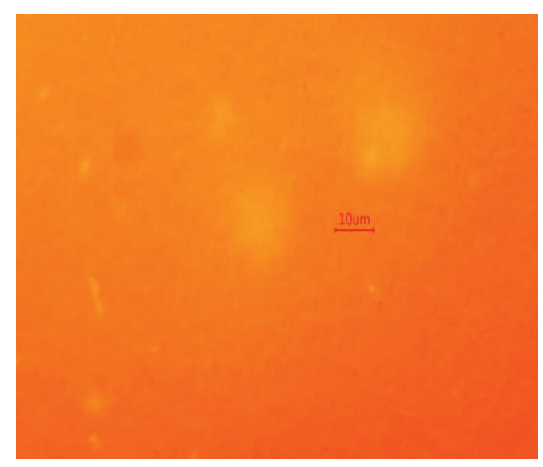

(c)

Figure 10: Fluorescence micrograph of different developmental times of the JG3 asphalt: (a) $0 \mathrm{~h}$; (b) $1 \mathrm{~h}$; (c) $1.5 \mathrm{~h}$.

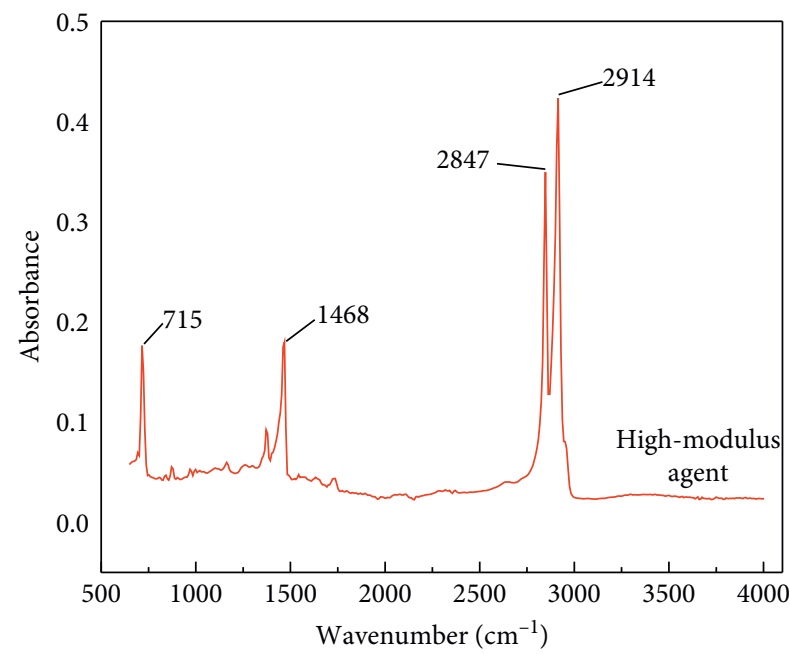

FIGURE 11: Infrared spectrum of the high-modulus agent.

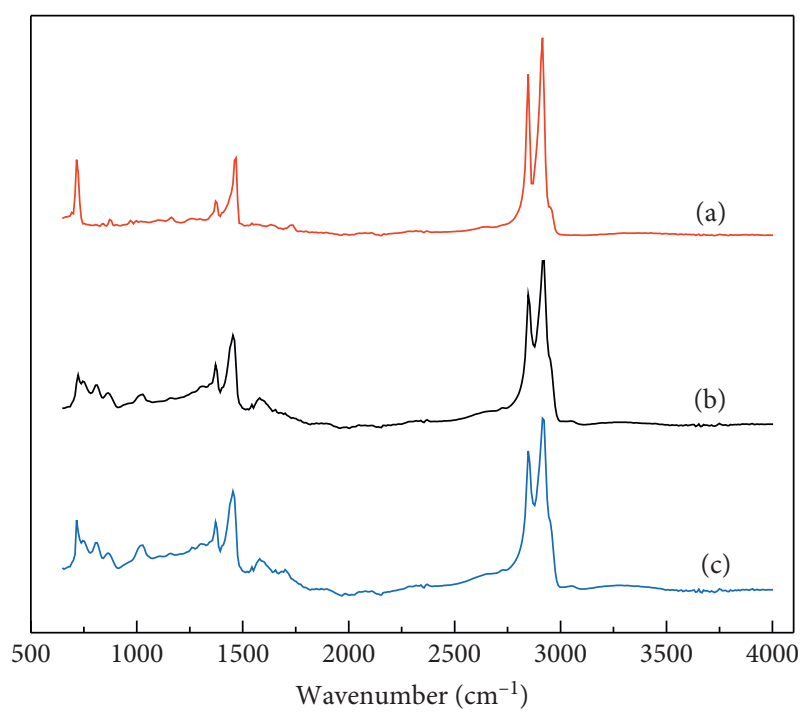

FIGURE 12: Infrared spectrum of (a) the high-modulus modifier, (b) the 70\# matrix asphalt, and (c) the high-modulus modified asphalt JG2. asphalt JG2. Therefore, it can be concluded that the modification of the base asphalt by adding the high-modulus modifier is purely physical blending modification, the modifier and the base asphalt are not chemically bonded, and no new substances are formed. This behavior is consistent with the macroscopic morphology observed by fluorescence microscopy. The high-modulus modifier only exhibits physical changes such as swelling of the matrix asphalt.

\section{Conclusions}

In this study, the rheological properties of high-modulus asphalt, 70\# asphalt, and SBS-modified asphalt, high-temperature performance of asphalt mixtures, and the modification mechanism of the high-modulus agent in the binder were discussed via a series of laboratory tests. The results confirm that HMAC has excellent road performance in high-temperature areas, and the following conclusions could be drawn:

(1) The addition of a high-modulus agent can significantly improve the high-temperature performance and viscoelastic properties of the asphalt binder and reduce the temperature sensitivity of the matrix asphalt to some extent. When the content of the high-modulus modifier increases to $6.67 \%$, the modified asphalt has better high-temperature performance than SBS-modified asphalt.

(2) The rutting resistance of HMAC is better than that of SBS-modified asphalt mixture, especially under high-temperature and heavy-load conditions. And the water stability of HMAC is better than that of SBS-modified asphalt mixture. The modulus of HMAC is higher than that of SBS-modified asphalt concrete under high and low temperature, which indicates that HMAC has good applicability in hightemperature range.

(3) By using the fluorescence microscopy test and infrared spectrum test, it can be found that the highmodulus agent particles develop by swelling in a high-temperature environment, absorbing the light components of asphalt. Some polymer chain 
segments of the modifier particles diffuse into the asphalt phase to form an interface layer, which slows down the movement of the molecules; some polymers can exhibit high stability and strong network structure with the asphalt molecular chain, which improves the high-temperature performance and viscoelastic property of the asphalt.

\section{Data Availability}

The experimental data used to support the findings of this study are included within the article.

\section{Conflicts of Interest}

The authors declare that there are no conflicts of interest regarding the publication of this paper.

\section{Acknowledgments}

The authors sincerely acknowledge the funding support from the National Natural Science Foundation of China (grant no. 51778140) and the Guangdong Provincial Department of Transportation (grant no. 2016-02-013).

\section{References}

[1] F. Ma and Z. Fu, "Application of hard asphalt and high modulus asphalt concrete in France," Journal of China \& Foreign Highway, vol. 28, no. 6, pp. 221-223, 2008, (in Chinese).

[2] M. Zheng, P. Li, J. Yang, H. Li, Y. Qiu, and Z. Zhang, "Fatigue character comparison between high modulus asphalt concrete and matrix asphalt concrete," Construction and Building Materials, vol. 206, pp. 655-664, 2019.

[3] F. Zhu and M. Zhang, "Analysis of HiMA popularization and application for african," Highway Engineering, vol. 34, no. 6, pp. 94-98, 2009, (in Chinese).

[4] R. Zhang, H. Wang, J. Gao, Z. You, and X. Yang, "High temperature performance of SBS modified bio-asphalt," Construction and Building Materials, vol. 144, pp. 99-105, 2017.

[5] H. J. Lee, J. H. Lee, and H. M. Park, "Performance evaluation of high modulus asphalt mixtures for long life asphalt pavements," Construction and Building Materials, vol. 21, no. 5, pp. 1079-1087, 2007.

[6] X. Wang, Y.-J. Qiu, S.-Y. Xue, Y. Yang, and Y. Zheng, "Study on durability of high-modulus asphalt mixture based on TLA and fibre composite modification technology," International Journal of Pavement Engineering, vol. 19, no. 10, pp. 930-936, 2018.

[7] T. Ma, H. Wang, X. Huang, Z. Wang, and F. Xiao, "Laboratory performance characteristics of high modulus asphalt mixture with high-content RAP," Construction and Building Materials, vol. 101, pp. 975-982, 2015.

[8] F. Xiao, D. Ma, J. Wang, D. Cai, L. Lou, and J. Yuan, "Impacts of high modulus agent and anti-rutting agent on performances of airfield asphalt pavement," Construction and Building Materials, vol. 204, pp. 1-9, 2019.

[9] W. Cao, S. Liu, and Y. Li, "Rutting-resistance performance of SBS and anti-rutting additive composite-modified asphaltconcrete mixtures," Journal of Testing and Evaluation, vol. 44, no. 2, pp. 921-929, 2016.
[10] M. Cheng, "Study on crack resistance and treatment measure of high modulus asphalt mixture," Highway Engineering, vol. 41, no. 5, pp. 46-51, 2016, (in Chinese).

[11] X. Wang, "Road performance of high modulus asphalt concrete additive calcium sulfate whisker," Journal of Chongqing Jiaotong University (Natural Sciences), vol. 30, no. 6, pp. 1331-1334, 2011, (in Chinese).

[12] D. Rys, J. Judycki, M. Pszczola, M. Jaczewski, and L. Mejlun, "Comparison of low-temperature cracks intensity on pavements with high modulus asphalt concrete and conventional asphalt concrete bases," Construction and Building Materials, vol. 147, pp. 478-487, 2017.

[13] G. Wang, L. Liu, and L. Sun, "Research on anti-deformation properties of high modulus asphalt concrete," Journal of Tongji University Natural Science, vol. 40, no. 2, pp. 02170222, 2012, (in Chinese).

[14] C. Si, H. Cao, E. Chen et al., "Dynamic response analysis of rutting resistance performance of high modulus asphalt concrete pavement," Applied Sciences, vol. 8, p. 2701, 2017.

[15] S. Chundi, Z. Xiaodong, Y. Zhanping et al., "Micro-mechanical analysis of high modulus asphalt concrete pavement," Construction and Building Material, vol. 220, pp. 128-141, 2019.

[16] L. Wang, P. Wang, Q. Xu et al., "Mechanism research on additives of high modulus asphalt mixtures," Journal of Chang'an University (Natural Science), vol. 35, no. 6, pp. 42-48, 2015, (in Chinese).

[17] P. Yang, Study on Properties of High Modulus Asphalt and its Mixture, South China University of Technology, Guangzhou, China, (in Chinese), 2012.

[18] Ministry of Transport of the People's Republic of China, Standard Test Methods of Bitumen and Bituminous Mixtures for Highway Engineering (JTG E20-2011) by the Ministry of Transport of the People's Republic of China, China Communication Press, Beijing, China, (in Chinese), 2011.

[19] Ministry of Transport of the People's Republic of China, Technical Specifications for Construction of Highway Asphalt Pavements (JTG F40-2004) by the Ministry of Transport of the People's Republic of China, China Communication Press, Beijing, China, (in Chinese), 2004.

[20] H. Yu, Z. Leng, Z. Zhou, K. Shih, F. Xiao, and Z. Gao, "Optimization of preparation procedure of liquid warm mix additive modified asphalt rubber," Journal of Cleaner Production, vol. 141, pp. 336-345, 2017.

[21] D. Wang, D. Li, J. Yan et al., "Rheological and chemical characteristic of warm asphalt rubber binders and their liquid phases," Construction and Building Materials, vol. 193, pp. 547-556, 2018.

[22] H. Wang, X. Liu, M. van de Ven, G. Lu, S. Erkens, and A. Skarpas, "Fatigue performance of long-term aged crumb rubber modified bitumen containing warm-mix additives," Construction and Building Materials, vol. 239, p. 117824, 2020.

[23] J. Yan, Z. Leng, C. Ling, J. Zhu, and L. Zhou, "Characterization and comparison of high-modulus asphalt mixtures produced with different methods," Construction and Building Materials, vol. 237, p. 117594, 2020.

[24] S. Hassanpour-Kasanagh, P. Ahmedzade, A. M. Fainleib, and A. Behnood, "Rheological properties of asphalt binders modified with recycled materials: a comparison with styrenebutadiene-styrene (SBS)," Construction and Building Materials, vol. 230, p. 117047, 2020.

[25] G. W. Loulizi, I. L. Flintsch, Q. Al- et al., "Comparing resilient modulus and dynamic modulus of hot-mix asphalt as material properties for flexible pavement design," Transportation 
Research Record Journal of the Transportation Research Board, vol. 1, pp. 161-170, 2006.

[26] H. P. Wang, J. Yang, X. Q. Shi et al., "Research on dynamic modulus and master curve of high modulus asphalt mixture," Journal of Highway and Transportation Research and Development, vol. 32, no. 8, pp. 12-18, 2015, (in Chinese).

[27] Y. Guo, F. Ni, and P. Xiao, "Dynamic rheological properties of modified asphalt based on linear viscoelastic range," Journal of Jiangsu University (Natural Science Edition), vol. 32, no. 4, pp. 460-463, 2011, (in Chinese).

[28] Y. Guo, L. Xu, L. Wu et al., "High temperature performance evaluation of modified asphalt based on multiple stress creep recovery test," Journal of Building and Material. vol. 21, no. 1, pp. 154-159, 2018, (in Chinese).

[29] A. Asif, A. Naveed, A. Muhammad et al., "Performance evaluation of bone glue-modified asphalt," Advances in Materials Science and Engineering, vol. 2019, p. 13, 2019.

[30] A. E. Alvarez, E. Ovalles, and A. Epps Martin, "Comparison of asphalt rubber-aggregate and polymer modified asphalt-aggregate systems in terms of surface free energy and energy indices," Construction and Building Materials, vol. 35, no. 10, pp. 385-392, 2012.

[31] X. Zou, A. Sha, W. Jiang, and X. Huang, "Modification mechanism of high modulus asphalt binders and mixtures performance evaluation," Construction and Building Materials, vol. 90, pp. 53-58, 2015.

[32] H. Yu, Z. Zhu, Z. Zhang, J. Yu, M. Oeser, and D. Wang, "Recycling waste packaging tape into bituminous mixtures towards enhanced mechanical properties and environmental benefits," Journal of Cleaner Production, vol. 229, 2019. 